\title{
Prediction of Coronary Artery Disease by Measurement of Circulating MicroRNA-423-3p Levels
}

\author{
Koh Ono, MD, PhD
}

I $\mathrm{n}$ this issue of the Journal, Wang et al demonstrate that circulating microRNA (miRNA; miR)-423-3p can improve the prediction of primary coronary artery disease (CAD) outcomes on the basis of a traditional risk factor model in the general population. ${ }^{1}$ First, they screened miRNA candidates to distinguish CAD from healthy controls using serum from patients with CAD and from control subjects. They utilized peripheral blood mononuclear cells (PBMCs) from control participants and vascular endothelial cells (ECs) treated with or without hypoxia to improve the specificity for screening. Next, the qualifying candidate miRNAs were measured in different samples collected from other hospitals, and the most reproducible

\begin{abstract}
Article p 1155
- miR-10a-5p and miR-423-3p - were then measured in a large-scale general population. Thus, circulating miR423-3p was found to improve the prediction of primary CAD outcomes on the basis of a traditional risk factor model.

The miRNAs constitute a class of small non-coding RNAs that inhibit protein expression by base pairing with complementary sequences located within the $3^{\prime}$ untranslated region of target mRNAs. ${ }^{24}$ miRNAs circulate in the blood stream enclosed in small vesicles called exosomes., ${ }^{\mathbf{5}}$ Thus,
\end{abstract}

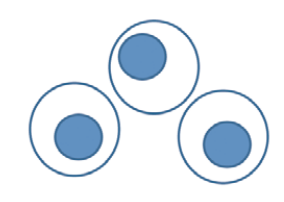

CAD/Control (PBMCs)

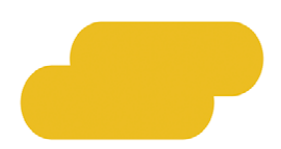

CAD/Control (Serum)

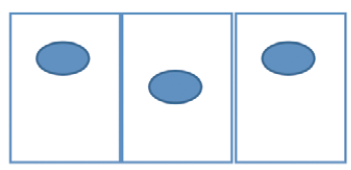

Hypoxic ECs/Control

L

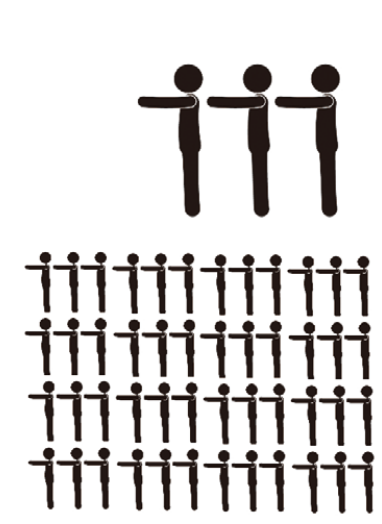

48 candidate miRNAs

CAD Patients ( $n=39 ; 48$ candidates)

5 positives

Large general cohort ( $n=2,812 ; 2$ candidates)

1 positive

\section{miR-423-3p}

Figure. Flow chart of the experimental strategy of this study. CAD, coronary artery disease; ECs, endothelial cells; PBMCs, peripheral blood mononuclear cells.

The opinions expressed in this article are not necessarily those of the editors or of the Japanese Circulation Society.

Received May 12, 2020; accepted May 12, 2020; J-STAGE Advance Publication released online May 28, 2020

Department of Cardiovascular Medicine, Graduate School of Medicine, Kyoto University, Kyoto, Japan

Mailing address: Koh Ono, MD, PhD, Department of Cardiovascular Medicine, Graduate School of Medicine, Kyoto University,

54 Shogoin-kawahara-cho, Sakyo-ku, Kyoto 606-8507, Japan. E-mail: kohono@kuhp.kyoto-u.ac.jp

ISSN-1346-9843 All rights are reserved to the Japanese Circulation Society. For permissions, please e-mail: cj@j-circ.or.jp 
these circulating miRNAs are stable in the blood, and there are several established methods for their extraction and measurement. There are already many reports, including ours, that show circulating miRNAs are good biomarkers for cardiovascular diseases. ${ }^{\mathbf{7}-\mathbf{1 0}}$

Because there are many circulating miRNAs, it is relatively difficult to select an important and useful miRNA for the prediction of cardiovascular diseases. One of the reasons for the success of this study is through its application of 2 different in vitro assays for the selection of candidate miRNAs, which enabled the authors to improve the specificity of their candidates (Figure). It is of note that utilization of these assays led to the findings on the source and mechanism of release of miR-423-3p. They showed that reduced miR-423-3p expression in ECs and in exosomes in EC culture medium after stimulation with tumor necrosis factor- $\alpha$ compared with control ECs and EC medium. They proposed that low production of miR-423-3p after inflammatory stimuli is the mechanism for serum changes in the levels of miR-423-3p in patients with CAD. However, miR-423-3p was also enriched in PBMCs, as shown in their data from the candidate screening. Therefore, further precise investigations are required to elucidate the source of miR-423-3p and the mechanisms for its production and release. It is already reported that circulating miR-423-5p can be used for circulating biomarker for heart failure.11 Because miR-423-5p is expressed with miR-423-3p and is expected to be more stable (http://www.mirbase.org/cgi-bin/ mirna_entry.pl?acc $=$ hsa-mir-423), it is interesting to investigate the levels of miR-423-5p in the same samples.

The other key success factor is that they confirmed their results in different groups of patients. They validated the results of their candidate miRNAs in 2 populations and finally evaluated the predictive ability of CAD in a large cohort. Because miR-423-3p is expressed in PBMCs and ECs, it is possible that miR-423-3p may be utilized for the prediction of other atherosclerotic diseases. It will also be interesting to determine whether there are similar results in other ethnic groups. As the authors indicate, it was reported that a combination of several miRNAs increased the predictive power for acute myocardial infarction. ${ }^{\mathbf{1 2 , 1 3}}$ Moreover, plasma miR-423-3p is reported to be upregulated in patients with prostate cancer. ${ }^{14}$ Thus, the addition of other biomarkers into the assessment might be beneficial for the prediction of cardiovascular diseases.

This study contains new information about potential serum biomarker for patients with CAD. However, the function of miR-423-3p is still not completely understood, especially in the development of atherosclerosis. It will be interesting to elucidate the roles of miR-423-3p in ECs and PBMCs by the generation of tissue-specific miR423-deficient mice.

\section{Financial Disclosures}

None.

\section{Disclosure}

K.O. is a member of Circulation Journal' Editorial Team

\section{References}

1. Wang X, Dong Y, Fang T, Wang X, Chen L, Zheng C, et al. Circulating microRNA-423-3p improves the prediction of coronary artery disease in a general population: Six-year follow-up results from China-Cardiovascular Disease Study. Circ J 2020; 84: $1155-1162$.

2. Lee RC, Feinbaum RL, Ambros V. The C. elegans heterochronic gene lin-4 encodes small RNAs with antisense complementarity to lin-14. Cell 1993; 75: 843-854.

3. Wightman B, Ha I, Ruvkun G. Posttranscriptional regulation of the heterochronic gene lin-14 by lin- 4 mediates temporal pattern formation in C. elegans. Cell 1993; 75: 855-862.

4. Horie T, Ono K, Horiguchi M, Nishi H, Nakamura T, Nagao K, et al. MicroRNA-33 encoded by an intron of sterol regulatory element-binding protein 2 (Srebp2) regulates HDL in vivo. Proc Natl Acad Sci USA 2010; 107: 17321-17326.

5. Valadi H, Ekstrom K, Bossios A, Sjostrand M, Lee JJ, Lotvall JO. Exosome-mediated transfer of mRNAs and microRNAs is a novel mechanism of genetic exchange between cells. Nat Cell Biol 2007; 9: 654-659.

6. Taylor DD, Gercel-Taylor C. MicroRNA signatures of tumorderived exosomes as diagnostic biomarkers of ovarian cancer. Gynecol Oncol 2008; 110: 13-21.

7. Kuwabara Y, Ono K, Horie T, Nishi H, Nagao K, Kinoshita M, et al. Increased microRNA-1 and microRNA-133a levels in serum of patients with cardiovascular disease indicate myocardial damage. Circ Cardiovasc Genet 2011; 4: 446-454.

8. Koyama S, Kuragaichi T, Sato Y, Kuwabara Y, Usami S, Horie $\mathrm{T}$, et al. Dynamic changes of serum microRNA-122-5p through therapeutic courses indicates amelioration of acute liver injury accompanied by acute cardiac decompensation. ESC Heart Fail 2017; 4: 112-121.

9. Soeki T, Yamaguchi K, Niki T, Uematsu E, Bando S, Matsuura $\mathrm{T}$, et al. Plasma microRNA-100 is associated with coronary plaque vulnerability. Circ $J$ 2015; 79: 413-418.

10. Natsume Y, Oaku K, Takahashi K, Nakamura W, Oono A, Hamada S, et al. Combined analysis of human and experimental murine samples identified novel circulating microRNAs as biomarkers for atrial fibrillation. Circ J 2018; 82: 965-973.

11. Tijsen AJ, Creemers EE, Moerland PD, de Windt LJ, van der Wal AC, Kok WE, et al. MiR423-5p as a circulating biomarker for heart failure. Circ Res 2010; 106: 1035-1039.

12. Bye A, Rosjo H, Nauman J, Silva GJ, Follestad T, Omland T, et al. Circulating microRNAs predict future fatal myocardial infarction in healthy individuals: The HUNT study. $J$ Mol Cell Cardiol 2016; 97: 162-168.

13. Cortez-Dias N, Costa MC, Carrilho-Ferreira P, Silva D, Jorge $\mathrm{C}$, Calisto C, et al. Circulating miR-122-5p/miR-133b ratio is a specific early prognostic biomarker in acute myocardial infarction. Circ J 2016; 80: 2183-2191.

14. Watahiki A, Macfarlane RJ, Gleave ME, Crea F, Wang Y, Helgason CD, et al. Plasma miRNAs as biomarkers to identify patients with castration-resistant metastatic prostate cancer. Int J Mol Sci 2013; 14: 7757-7770. 